\title{
Second-Order Latent Growth Models with Shifting Indicators
}

Gregory R. Hancock

University of Maryland, ghancock@umd.edu

Michelle M. Buehl

University of Maryland, mbuehl@gmu.edu

Follow this and additional works at: http://digitalcommons.wayne.edu/jmasm

Part of the Applied Statistics Commons, Social and Behavioral Sciences Commons, and the Statistical Theory Commons

\section{Recommended Citation}

Hancock, Gregory R. and Buehl, Michelle M. (2008) "Second-Order Latent Growth Models with Shifting Indicators," Journal of Modern Applied Statistical Methods: Vol. 7 : Iss. 1 , Article 5.

DOI: $10.22237 /$ jmasm/1209614640

Available at: http://digitalcommons.wayne.edu/jmasm/vol7/iss1/5 


\section{Second-Order Latent Growth Models with Shifting Indicators}

\author{
Gregory R. Hancock \\ University of Maryland
}

\author{
Michelle M. Buehl \\ George Mason University
}

Second-order latent growth models assess longitudinal change in a latent construct, typically employing identical manifest variables as indicators across time. However, the same indicators may be unavailable and/or inappropriate for all time points. This article details methods for second-order growth models in which constructs' indicators shift over time.

Key words: latent growth modeling; structural equation modeling; curve-of-factors models.

\section{Introduction}

Applying structural equation modeling (SEM) techniques to the study of change has become a particularly powerful method for analyzing change over time. Specifically, a special parameterization of SEM called latent curve analysis or latent growth modeling (LGM) has proven to be an extremely flexible approach to study a variety of growth and change questions. LGM provides estimates of many substantively important aspects of change, such as the status of individuals at some substantively interesting temporal reference (e.g., initial measurement point), their growth or change trajectory over time, and the amount of individual variability at a reference point and in rates of growth.

Although techniques such as hierarchical linear modeling can offer such information, LGM also allows one to examine latent correlates or latent predictors of these

Gregory R. Hancock is Professor and Chair in the Department of Measurement, Statistic and Evaluation. His interests include structured means models, latent variable models, and latent growth models. Email: ghancock@umd.edu. Michelle M. Buehl is an Associate Professor of Educational Psychology. Her interests are in student and teacher beliefs, learning, motivation, and academic development. Email her at mbuehl@gmu.edu growth parameters. Thus, one may not only estimate the form and nature of intra- and interindividual growth over time, but also test the contribution of other constructs to these growth processes. Further, the flexibility offered by LGM allows for the testing of diverse error structures (e.g., auto-regressive), allows means and variances to change over time, and thus provides a unified assessment of many aspects of change. The basic principles and applications of these models are discussed in several useful didactic sources (e.g., Bollen \& Curran, 2005; Byrne \& Crombie, 2003; Duncan, Duncan, \& Strycker, 2006; Hancock \& Lawrence, 2006; Preacher, Wichman, MacCallum, \& Briggs, 2008).

Whereas traditional growth models evaluate change in a single measured variable over time, a more complex parameterization evaluates growth in a single unmeasured latent variable (i.e., factor or construct) over time, where that factor has the same multiple measured indicators at each time point. For example, if a child development researcher gathered data using the same five childhood aggression scales at multiple time periods, one could specify relations from, say, an initial status factor and a linear growth factor to each of the latent constructs at each time period. This model has the benefit of analyzing growth using latent constructs disattenuated from measurement error, error that would be present when analyzing only one of the repeated manifest scale values or even some aggregate across scales. Such a model has been referred to as a "curve-of-factors model" (McArdle, 1988), a 


\section{SECOND-ORDER LATENT GROWTH MODELS WITH SHIFTING INDICATORS}

"latent variable longitudinal curve model" (Tisak \& Meredith, 1990), and, because there are two levels of latent constructs but only one level of manifest indicators, a "second-order latent growth model" (Hancock, Kuo, \& Lawrence, 2001; Sayer \& Cumsille, 2001).

To elaborate briefly, for change being assessed across $T$ time points, let $\eta_{t}$ be a latent construct indicated at time $t$ by $J$ measured variables $Y_{t j}(j=1, \ldots, J)$. That is, $\mathbf{y}=\boldsymbol{\tau}+\boldsymbol{\Lambda} \boldsymbol{\eta}+\boldsymbol{\varepsilon}$, where the vector $\mathbf{y}$ contains $T$ sets of values across time for $J Y$ variables, $\tau$ is a vector of variable intercepts, $\Lambda$ is a matrix of loadings relating each $\eta_{t}$ construct to its measured variable indicators, $\eta$ is a vector of the $\eta_{t}$ constructs, and $\varepsilon$ is a vector of random normal errors. So far, this is simply a conventional firstorder confirmatory factor model with its mean structure modeled simultaneously.

As for modeling growth in the $\eta_{t}$ constructs, it can be described by $\eta=\Gamma \xi+\zeta$, where $\Gamma$ is a matrix of second-order factor loadings reflecting the hypothesized growth pattern underlying the $\eta_{t}$ constructs, $\xi$ is a vector of exogenous latent factors capturing the facets of growth being modeled, and $\zeta$ is a vector of random normal disturbances in the first-order $\eta_{t}$ constructs. As an example, a model could posit that $\xi=\left[\begin{array}{ll}\alpha & \beta\end{array}\right]$, where $\alpha$ is an intercept factor representing the true initial amount of $\eta$ and where $\beta$ is a slope factor representing the true rate of linear change in $\eta$ over time. If the indicators of this $\eta$ construct are measured at four equal-interval time points, a test for linear growth in the construct could be conducted by fitting second-order factor loadings $\Gamma$ with $\left[\begin{array}{ll}1 & 1\end{array}\right.$ $\left.\begin{array}{ll}1 & 1\end{array}\right]^{\prime}$ in its first column and $\left[\begin{array}{llll}0 & 1 & 2 & 3\end{array}\right]^{\prime}$ in its second. Of course, nonlinear models may be accommodated in this framework as well, as can unequally spaced times points, precisely paralleling first-order growth models.

The illustrative second-order latent growth model described above, referred to herein as Model 1, is depicted in Figure 1. Indicator variables $A$ through $E$ are measured at each of four equal-interval time points. First-order loadings $\lambda$ are constrained equal across constructs, as are first-order intercepts $\tau$. As explained elsewhere (e.g., Hancock et al., 2001), indicator variables used to identify factor scales do not require intercepts. Potential variations in this model include the imposition of error variance constraints on the same variable over time, disturbance variance constraints, error covariances for corresponding variables over time (with or without equality constraints), unequally spaced time intervals, alternative temporal reference points, and the inclusion of nonlinear growth constructs. There are five key parameters in this model as specified: $\kappa_{\alpha}$ and $\kappa_{\beta}$, the means of the intercept and slope factors, respectively; $\psi_{\alpha}$ and $\psi_{\beta}$, the variances of the intercept and slope factors (through their disturbances), respectively; and $\psi_{\alpha \beta}$, the covariance between the intercept and slope factors. This type of model serves as the foundation for a case in which the same variables are not used across all time points, as detailed next. [Note that in Figure 1, as well as Figures 2, 4, and 5, there appear two pseudovariables (unit constants, depicted as a 1 in a triangle). Although common notation utilizes a single such symbol in a given path diagram, two are used here to reduce clutter in each figure.]

\section{Shifting indicators}

In all treatments of second-order growth models (e.g., Hancock et al., 2001; McArdle, 1988; Sayer \& Cumsille, 2001; Tisak \& Meredith, 1990), the assumption is that identical manifest indicators are available at each time period. However, for a variety of phenomena in the social sciences, such an assumption may be unreasonable (see, e.g., McArdle, 1994). For example, when assessing fear responses from infancy through early childhood to ascertain if children become more or less fearful over time, as well as the determinants of such development, the process of eliciting and measuring a fear response must differ at different ages.

Quite simply, some stimuli that frighten a 6-month old might not frighten the child when reaching 12 or 18 months of age, and children might not demonstrate fear in the same manner over time as their ability to communicate develops. 
HANCOCK \& BUEHL

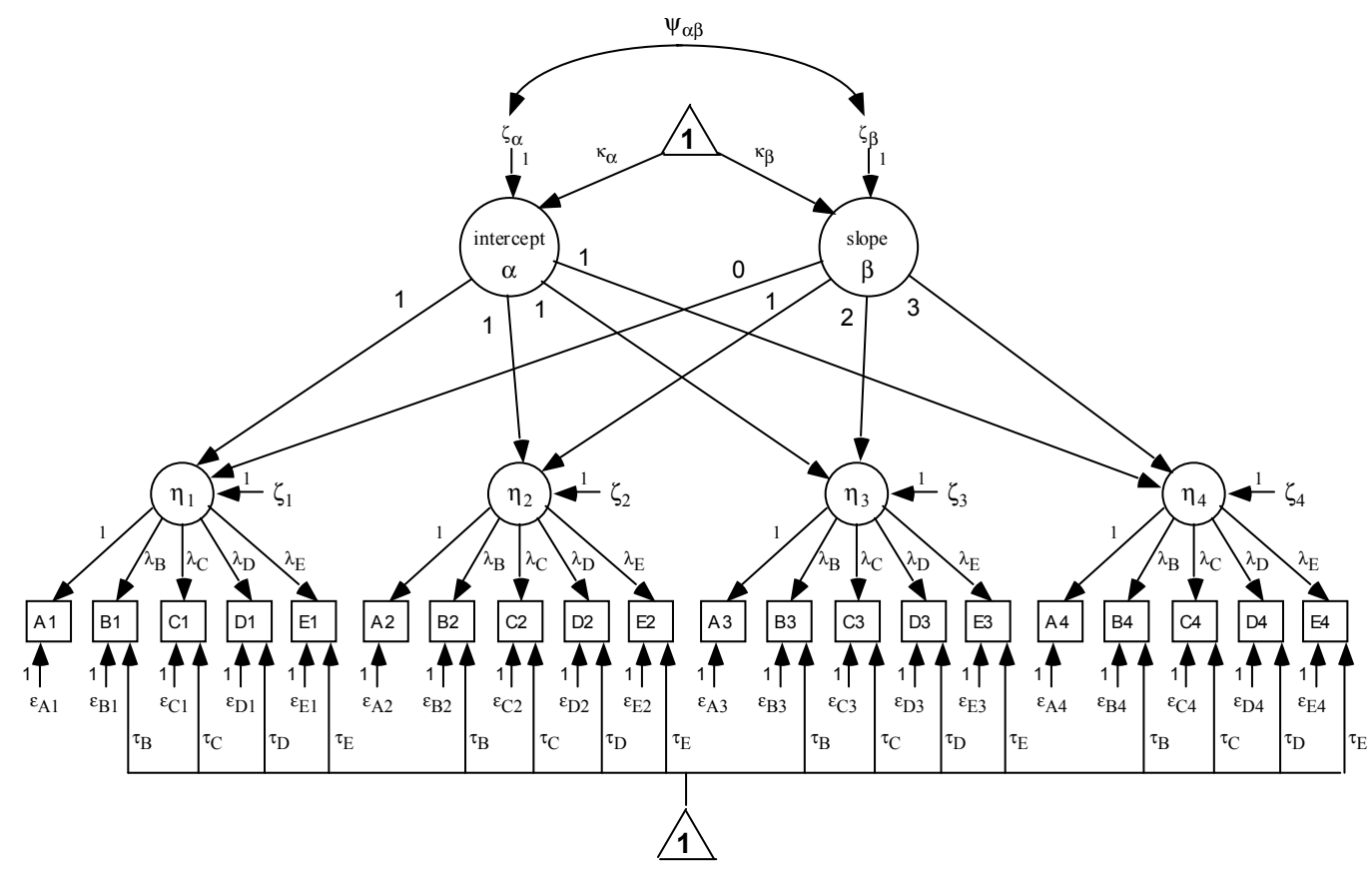

Figure 1. Standard second-order latent growth model ("Model 1")

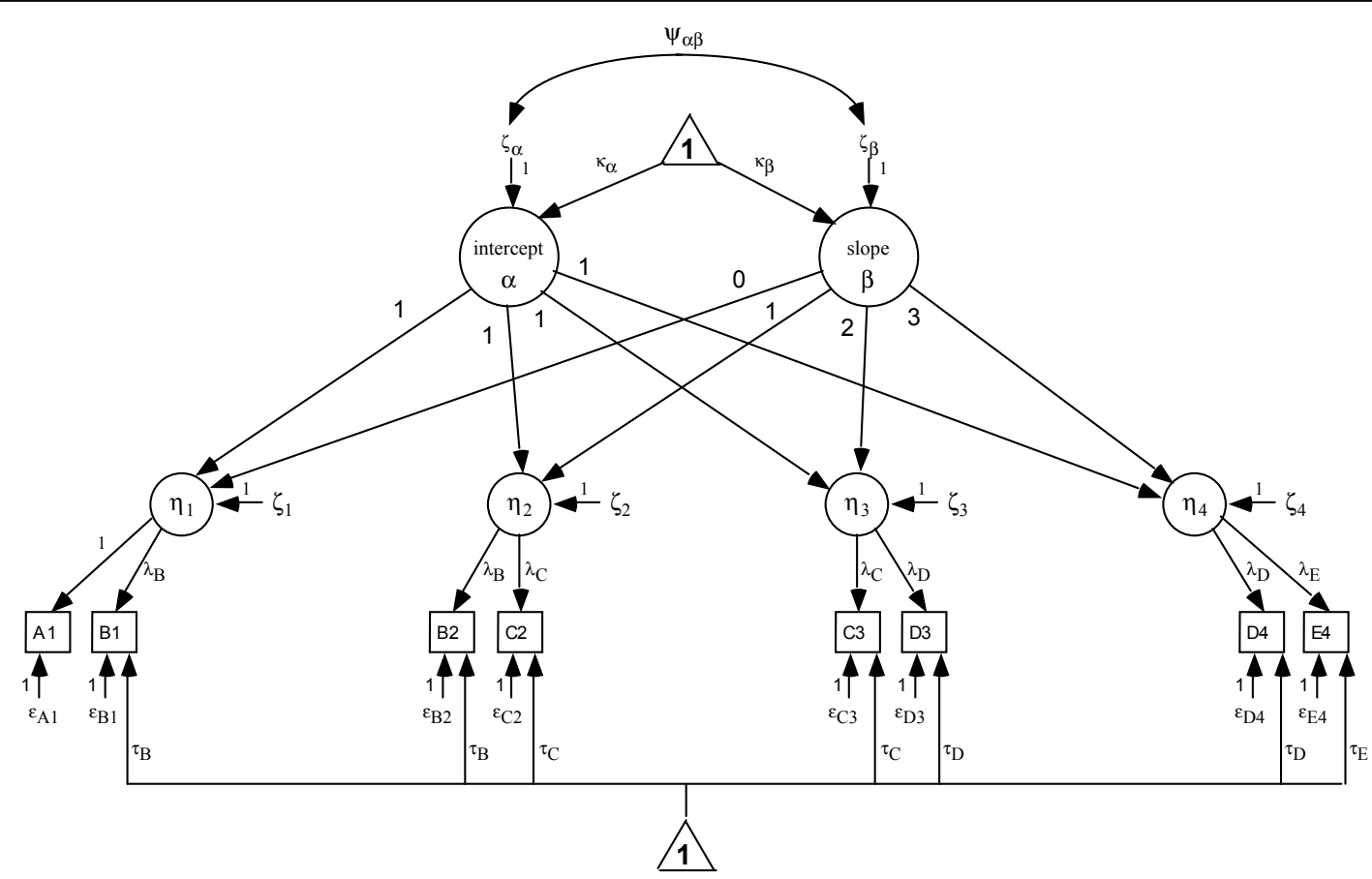

Figure 2. Second-order latent growth model with shifting indicators ("Model 2") 


\section{SECOND-ORDER LATENT GROWTH MODELS WITH SHIFTING INDICATORS}

Similarly, when administering survey items to children over a time period before and after becoming literate, rating scales may start with oral administration by a teacher, follow later by having the child circle "smiley face" responses, and ultimately end by having the child circle verbal descriptors. As a final example, an organization assessing employee satisfaction longitudinally might find that the wording of some of the items falls out of common usage. This was the case with the very popular Job Descriptive Index (JDI), where several satisfaction items were changed because the wording of some items was no longer in the popular vocabulary (Smith et al., 1987). Thus, reminiscent of issues of equating in item response theory (see, e.g., Kolen \& Brennan, 2004), what is needed here is a way of analyzing growth when the latent construct is conceptualized to be the same over time but the manifest indicators shift or change.

Consider the developmental researcher who wishes to investigate growth in a latent construct across equally-spaced time points in children's lives, and ideally would like to be able to obtain the same five measurements at each time as depicted in Figure 1 (i.e., measures A, B, C, D, and E). Thus, the same five indicator variables would be used at each time point in a second-order latent growth model, with corresponding first-order loadings and intercepts constrained equal over time. Imagine, however, that at Time 1 only measures $\mathrm{A}$ and $\mathrm{B}$ are developmentally appropriate; that is, the child is not yet ready to face the stimuli or tasks required for measures C, D, and E. Further, at Time 2, measure $\mathrm{A}$ is now too simple and only measures $\mathrm{B}$ and $\mathrm{C}$ are developmentally appropriate; D and $\mathrm{E}$ are still too advanced; and so forth. So, the indicators are shifting as required by developmental considerations, and the actual set of available indicator variables is thus as follows:

$\begin{array}{llll}\frac{\text { Time } 1}{\text { A1 }} & \text { Time } 2 & \text { Time } 3 & \text { Time } 4 \\ \text { B1 } & \text { B2 } & & \\ & \text { C2 } & \text { C3 } & \\ & & \text { D3 } & \text { D4 } \\ & & & \text { E4 }\end{array}$

Notice first that Time 1 and Time 3 share no common indicators, nor do Time 2 and Time 4. However, there is overlap between adjacent time points, such that each construct is linked to its temporal neighbor through a common indicator variable. Linking among constructs, of which many forms exist (as discussed below), will be necessary to facilitate model identification for a second-order growth model with shifting indicators. The model just described, referred to herein as Model 2, is depicted in Figure 2 above.

In addition to the lack of any common indicators across all time points, many features are noteworthy about Model 2. First, and as before, corresponding loadings and intercepts are constrained equal across time; such invariance is crucial for the shifting indicator model to function properly. In the full model, Model 1, variable A was chosen as the scale indicator for all factors. In Model 2 where indicators shift, even though only the first construct has variable A as an indicator, it is still, in fact, the scale indicator for all factors by virtue of the loading constraints across factors. A one unit increase in $\eta_{1}$ yields a one unit increase in $A(\mathrm{~A} 1)$ and a $\lambda_{\mathrm{B}}$ unit increase in $\mathrm{B}$ (B1); a one unit increase in $\eta_{2}$ also yields a $\lambda_{B}$ unit increase in B (B2), as well as a $\lambda_{C}$ unit increase in $C(C 2)$; a one unit increase in $\eta_{3}$ also yields a $\lambda_{\mathrm{C}}$ unit increase in $\mathrm{C}(\mathrm{C} 3)$, as well as a $\lambda_{\mathrm{D}}$ unit increase in D (D3); a one unit increase in $\eta_{4}$ also yields a $\lambda_{D}$ unit increase in D (D4), as well as a $\lambda_{E}$ unit increase in $E(E 5)$.

Thus, all variables are linked back to the first construct through equality constraints on $\lambda_{\mathrm{B}}, \lambda_{\mathrm{C}}$, and $\lambda_{\mathrm{D}}$, and to the units assigned the first construct through its scale indicator. Note also that any other variable could have been chosen as the scale indicator, resulting only in a change of the metric of parameters' solutions. If variable $B$ had been selected, for example, it would have a unit loading on both $\eta_{1}$ and $\eta_{2}$, thereby constraining those loadings implicitly; the $\mathrm{C}$ and $\mathrm{D}$ loadings would be constrained explicitly with formal equality constraints, while the $\mathrm{A}$ and $\mathrm{E}$ loadings would be free. Whether A or $\mathrm{B}$ is chosen as the scale indicator, or any other variable for that matter, only four unique loadings are estimated. 


\section{HANCOCK \& BUEHL}

Second, with regard to intercepts, corresponding parameters are constrained over time just as in Model 1, and variables assigned the role of scale indicator have no intercept term estimated. In Model 2, just as in the full model, only four intercepts will be estimated: one for each variable other than the system's scale indicator.

Third, just as in Model 1, there are five key parameters to be estimated: $\kappa_{\alpha}$ and $\kappa_{\beta}$, the means of the intercept and slope factors, respectively; $\psi_{\alpha}$ and $\psi_{\beta}$, the variances of the intercept and slope factors (through their disturbances), respectively; and $\psi_{\alpha \beta}$, the covariance between the intercept and slope factors. As will be illustrated below, the parameters estimated under this reduced model with shifting indicators are the same as those under the full model.

Finally, many variations and extensions to this model are possible. Error variances for the same variable may be constrained over time, reflecting comparable measurement error in each variable across time. Similarly, disturbance variances in the first order constructs may be constrained equal. Also, error covariance parameters may be estimated for corresponding variables over time (with or without equality constraints). Unequally spaced time intervals may be accommodated, alternate temporal reference points may be employed, and nonlinear growth constructs may be included under similar configurations. And lastly, as discussed below, many configurations of linked variables could make such a model identified.

Configuration requirements for shifting indicators

As mentioned earlier, many practical reasons might give rise to a shifting set of indicator variables. Developmental necessities, for example, could yield a pattern as seen in Model 2. Administrative decisions within a company, on the other hand, could change the content of the evaluation instruments as new issues arise. In fact, one could simply encounter a loss or corruption of data gathered at different points in time, or errors in measure administration could result in some items being mistakenly omitted from a survey. Regardless of the mechanism giving rise to the particular shifting pattern of the indicators, all factors must be linked to each other through loading constraints (equality or unit scaling) either directly or indirectly; otherwise a consistent metric for constructs is not preserved over time.

In most practical situations, one could most likely inspect the available indicators at each time point to see if adequate construct linking exists. In more complex longitudinal systems, however, establishing the necessary linking might be less clear by inspection alone. A heuristic is thus offered for establishing this sufficient condition. Consider a first-order factor repeated over $T$ time points, with $J_{t}$ indicators at each time. All first-order factor loadings are in matrix $\Lambda$, which has ${ }_{t=1}^{T} J_{t}$ rows and $T$ columns. Figure 3 depicts the loading matrix for Model 2 from Figure 2. The information in $\Lambda$ may be abbreviated in a symbolic $p \times T$ configuration matrix $\mathbf{C}$, where $p$ is the number of unique variables across all $T$ time points (i.e., the number of distinct elements in the union of the $T$ indicator sets, each of which has $J_{t}$ elements). The $5 \times 4$ configuration matrix $\mathbf{C}$ for Model 2 is also shown in Figure 3, where asterisks indicate a variable loading on a construct at one or more time points. Next, from $\mathbf{C}$ a $T \times T$ incidence matrix $\mathbf{M}$ may be derived such that, for $t=1$ to $T$ and $u=1$ to $T$, element $m_{t u}=1$ if the $t$ th and $u$ th constructs have one or more common constrained indicator variables (measured at times $t$ and $u$ ) and element $m_{t u}=0$ otherwise. If $t=u$, then obviously $m_{t u}=1$. The incidence matrix M for Model 2 appears in Figure 3. Finally, drawing from Markov-chain treatments of the decomposition of a state-space into equivalence classes (see, e.g., Ross, 2000), a heuristic for assessing whether sufficient linkages exist among constructs comes by assessing whether matrix $\mathbf{M}$ is irreducible. Specifically, if raising $\mathbf{M}$ to the $T$ th power yields a matrix with all positive elements, then the matrix is irreducible and sufficient linkages exist. If, however, any zero elements are present in $\mathbf{M}^{T}$, then the constructs are not all linked, and a second-order growth model with shifting indicators cannot be fit to the data. Because elements $e_{t u}$ in $\mathbf{M}^{T}$ are all nonnegative, this operationalizes sufficient 


\section{SECOND-ORDER LATENT GROWTH MODELS WITH SHIFTING INDICATORS}

linkage as $\underset{t=1}{\subseteq} \bigodot_{u=1}^{T} e_{t u}>0$. Although in the case of Model 2 inspection alone is enough to establish sufficient construct linkage, as shown in Figure 3 the resulting matrix $\mathbf{M}^{T}$ contains all positive elements.
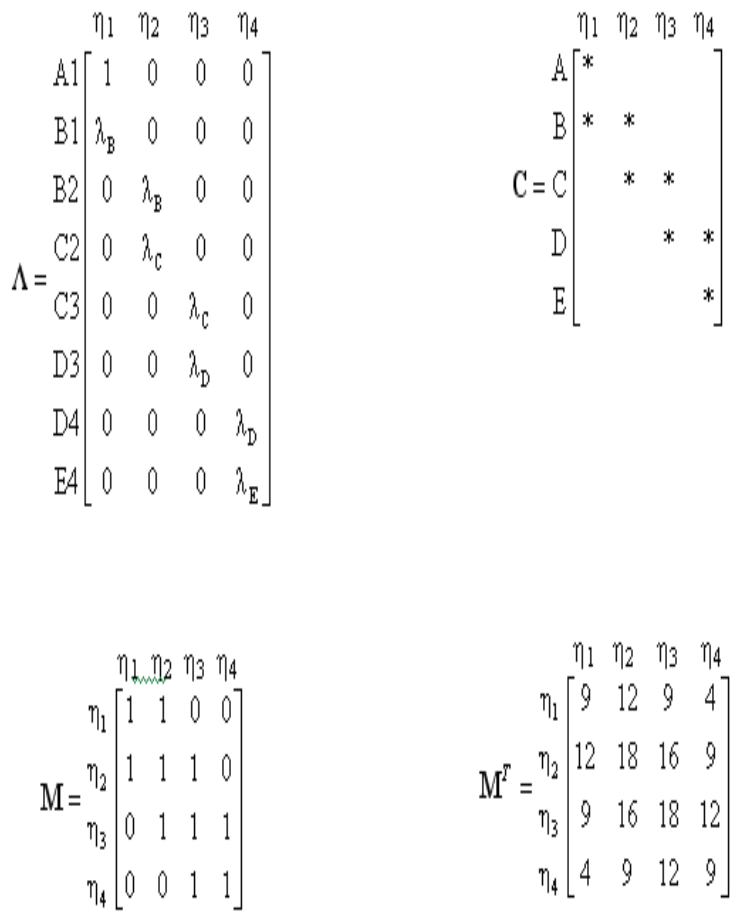

Figure 3. Matrices associated with Model 2

It should be also noted that the above criterion of incidence matrix irreducibility does not actually constitute a minimum condition for model identification. Regardless of how many indicators are present at each of the $T$ time points, the minimum condition for model identification requires that $T-1$ pairwise constraints (equality or unit scaling) must exist and in a specific configuration. This can be operationalized using the elements below the diagonal of the incidence matrix $\mathbf{M}$, requiring that a minimum of $T-1$ nonzero elements be arranged such that every combination of $t$ th row and $u$ th column has at least one nonzero lower triangular element in its union (note that multiple such configurations exist). Put simply, if one draws horizontal and vertical lines through and beyond each of the $T-1$ nonzero entries below the diagonal of $\mathbf{M}$, minimum identification conditions have been met if and only if every lower-triangular cell has at least one line passing through it. This heuristic of course works with more than the minimum $T$-1 constraints as well.

Examples

Two examples are offered in this section. The first is for a population matrix in which five indicators are present at each of four time points. This model will be analyzed in a full second-order latent growth model form as in Model 1, and a minimal reduced form as in Model 2, showing key parameters to be equivalent in both solutions. The second example will draw from the National Education Longitudinal Survey of 1988 (NELS:88) data set, sponsored by the National Center for Educational Statistics, U.S. Department of Education (see Ingels, Dowd, Baldridge, Stipe, Bartot, \& Frankel, 1994). In this example, sample data for four indicators are present at each of three time points. The model will be analyzed in full second-order latent growth model form, and then all possible minimal reduced forms (using the same scale indicator). Summary information for all reduced forms will be presented and compared to the results from the full sample.

\section{Example 1: Contrived Population Data}

Population data were created for all 20 variables in Model 1, where the same five indicators are used for a factor at each of four equally-spaced time points. These data, which consist of a $20 \times 20$ population covariance matrix and 20 population means, are embedded within the EQS 6.1 syntax (Bentler, 2004) for this example presented in Appendix A. [This model could be run in any standard SEM software; EQS was chosen merely for illustration as seen in Appendices A and B.] Note that in this program the sample size for this population was arbitrarily set to 100,000 ; this choice does not affect parameter estimation.

A full second-order latent growth model was imposed upon the data as shown in Figure 1 (with intercept factor $\alpha$, linear growth factor $\beta$, and loading and intercept constraints), and allowed error covariances between residuals of 


\section{HANCOCK \& BUEHL}

common indicators at multiple time points (e.g., $\left.\varepsilon_{\mathrm{A} 1}, \varepsilon_{\mathrm{A} 2}, \varepsilon_{\mathrm{A} 3}, \varepsilon_{\mathrm{A} 4}\right)$. No variance or covariance equality constraints were imposed. This model resulted in perfect data-model fit (given the contrived nature of the data) and yielded the following (expected) key parameter solutions: $\kappa_{\alpha}=1.400, \kappa_{\beta}=0.700, \psi_{\alpha}=0.490, \psi_{\beta}=0.490, \psi_{\alpha \beta}=$ -0.098 .

Now imagine having population data for only the eight indicators in the shifting indicator model as depicted in Figure 2. These data, which consist of an $8 \times 8$ population covariance matrix and eight population means, are embedded within the EQS 6.1 syntax (Bentler, 2004) for this example also presented in Appendix A. Again the sample size for this population was arbitrarily set to 100,000 .

A second-order latent growth model with shifting indicators was imposed as shown in Figure 2 (intercept factor $\alpha$, linear growth factor $\beta$, intercept and loading constraints). As before the A variable loading is set to unity, but in this case there is only one A variable, that at the first time point (i.e., A1). Even though this model does not have the same indicator variables directly present across factors, and even though there is no loading fixed to unity for the construct at times 2, 3, and 4, a solution emerges that is identical to that from the full set: $\kappa_{\alpha}=1.400, \kappa_{\beta}=0.700, \psi_{\alpha}=0.490, \psi_{\beta}=0.490, \psi_{\alpha \beta}=$ -0.098. As discussed previously, this phenomenon arises because the imposition of constraints effectively forces the first factor's scale indicator A1 to be the scaling indicator for all constructs even though variable A does not load on them. Further, any set of indicators meeting the configuration criteria previously described will yield identical parameter solutions as long as variable A provides scale directly and indirectly to all first-order factors. Thus, the shifting indicator model can capture the parameter estimates using only a subset of the indicators.

Example 2: NELS Data for Full and Reduced Second-Order Growth Models

As a second illustration of second-order growth models with shifting indicators, data from 228 females from the NELS:88 data set were used. Specifically, the construct of selfconcept was assessed at 8th, 10th, and 12th grades, using a variety of indicator variables. Four indicator variables were selected that seemed most theoretically related to students' self-concept. These items were based on Rosenberg's (1965) widely used measure of self-esteem and included: "On the whole, I feel good about myself;" "I feel I am a person of worth;" "On the whole, I feel satisfied with myself;" and "At times, I think I am no good at all." Respectively, these are items 44A, 44D, $44 \mathrm{H}$, and 44J from 8 th grade, 62A, 62D, 62H, and $62 \mathrm{~J}$ from 10 th grade, and $66 \mathrm{~A}, 66 \mathrm{D}, 66 \mathrm{H}$, and $66 \mathrm{~J}$ from 12 th grade. All measures utilized a four-point Likert format; for the current example all responses were recoded such that a higher numerical response on a variable represented a more positive self-concept. Although a compelling argument could be made for treating these data as ordinal, we will treat them as intervally scaled measures for the purposes of illustration. Summary statistics for these data are embedded within the EQS 6.1 syntax (Bentler, 2004) for this example, presented in Appendix B.

First, as a frame of reference, a secondorder latent growth model was fit to these data as shown in Figure 4, with intercept factor $\alpha$ and linear growth factor $\beta$, assuming equally-spaced time points, constraining first-order loadings and intercepts to be equivalent across shared (adjacent) time points, constraining error variances for common variables and first-order disturbance variances to be equal over time, allowing nonzero error covariances for common indicator variables over time (not shown in figure), and using variable $\mathrm{J}$ (i.e., 44J, 62J, 66J) as the first-order factors' scale indicator.

The comparative fit index (CFI) and root mean-square error of approximation (RMSEA), as well as key parameter estimates for the full model, appear in Table 1. By even the most modern and rigorous of standards (e.g., $\mathrm{Hu} \&$ Bentler, 1999), this data-model fit was excellent. The parameter estimates indicate interesting 



Figure 5. Example of second-order latent growth model with shifting indicators, for NELS:88 data 


\section{HANCOCK \& BUEHL}

intercept behavior, but rather uninteresting slope behavior (small mean and variance, neither statistically significant). This is probably due to the very stable nature of global self-esteem assessed by the Rosenberg (1965) measure.

Second, using the same NELS: 88 data for 228 females, a complete set of shifting indicator models was conducted with the following characteristics: only two indicators were present at each time point, no variable appeared at more than two time points, adjacent time points were linked with a single common indicator variable, and variable $\mathrm{J}$ was present in all models as the scale indicator (appearing either at one or two time points). As with the full model, each of these minimal shifting indicator models had corresponding loadings, intercepts, and error variances constrained, as well as error covariances between common indicators' residuals at adjacent time points and constrained first-order disturbance variances. A total of 24 such configurations existed and were run on these data; an example of such a model is depicted in Figure 5. Summaries of data-model fit as well as means and medians of key parameter estimates are presented in Table 1.

Whereas the previous example illustrated that population values will be identical for the full and reduced models, sample values will vary across reduced models. This is because the full model imposes constraints across factors at all time points (i.e., their indicators' loadings, intercepts, and error variances), but in these reduced models such constraints exist only in temporally adjacent factors. Thus, in applied scenarios when data exist with only select indicators available at each time point, and in a shifting but linked configuration, one can expect results to be somewhat dependent upon the variables at hand. Still, in the current example when averaging across all of the reduced models, the typical inferences regarding each of the key parameter estimates do match those of the full model. In general, such coherence will be expected to be enhanced the more the model at hand, and all its constraints, constitute a sound approximation to the true growth process operating in the population, as is true in any latent variable model.

\section{Discussion}

The methods presented in the current article have roots in several related areas of modeling. Certainly the principles of latent growth modeling for measured variables, and in particular their second-order adaptation for growth in latent variables, are foundational. Also related are growth modeling methods for accelerated longitudinal designs with measured (or latent) variables (see, e.g., Duncan, Duncan, \& Hops, 1996; McArdle, 1994; McArdle \& Bell, 2000; McArdle \& Hamagami, 1991; McArdle \& Woodcock, 1997). In such designs interest still resides in gaining an understanding of development over $T$ time points, but specifically in doing so without following the same group of individuals for the entire period. Rather, concurrent cohorts of individuals with adjacent and overlapping subsets of time points (e.g., Cohort 1 at ages 4, 5, and 6, Cohort 2 at ages 6 , 7, and 8, and Cohort 3 at ages 8, 9, and 10) are essentially spliced together through constraints on common parameters within a multisample latent growth model. The current work also effectively splices together parts of a model by constraining common parameters, but does so all within a single sample followed for the entire $T$ time points. The need for the current method's splicing arises because one is faced with staggered subsets of ("shifting") indicator variables perhaps due to indicators' unavailability or their developmental inappropriateness. As such constructs' common parameters across different time points are constrained in an attempt to give constructs a common identity and thus be able to model growth therein. Minimum constraint conditions involving the incidence matrix $\mathbf{M}$ were presented in this article (and which can, in fact, easily be adapted for accelerated longitudinal designs).

The need for parameter constraints and a common identity for factors also brings up the larger (and much thornier) issue of factorial invariance, both from theoretical and statistical perspectives. First, addressing the theoretical, the second-order latent growth model with shifting indicators is predicated upon the assumptions that (1) the same unidimensional construct exists at all time points, and (2) that 
SECOND-ORDER LATENT GROWTH MODELS WITH SHIFTING INDICATORS

Table 1

Parameter Estimates for Full and Reduced NELS:88 Growth Models

\begin{tabular}{lccc}
\hline & $\begin{array}{l}\text { Full model } \\
\text { estimate }\end{array}$ & $\begin{array}{c}\text { Shifting model } \\
\text { mean estimate }\end{array}$ & $\begin{array}{c}\text { Shifting model } \\
\text { median estimate }\end{array}$ \\
\hline CFI & .969 & .987 & 1.000 \\
RMSEA & .039 & .015 & .000 \\
$\kappa_{\alpha}$ & $2.746^{*}$ & $2.730^{*}$ & $2.671^{*}$ \\
$\kappa_{\beta}$ & .011 & .028 & .027 \\
$\psi_{\alpha}$ & $.044^{*}$ & $.094^{*}$ & $.077^{*}$ \\
$\psi_{\beta}$ & .006 & .017 & .012 \\
$\psi_{\alpha \beta}$ & .002 & -.018 & -.008 \\
$* p<.05$ & & & \\
\hline
\end{tabular}

are adequate to draw inference regarding said construct. If a researcher believes that, for example, the nature of fear in children transforms with age, or that the new survey items do not quite reflect the same construct as those used previously, then the techniques illustrated here should not be used.

Second, regarding the statistical issues of factorial invariance, one might wonder what level of invariance is necessary to give us confidence that the same construct does indeed exist at all time points. Should all common loadings, intercepts and error variances be constrained equal, representing strict factorial invariance? Should just common loadings and intercepts be constrained, representing strong factorial invariance (Meredith, 1993)? May loadings alone be constrained, representing weak factorial invariance (Widaman \& Reise, 1997)? May only some loadings and intercepts be constrained, yielding partial loading invariance and partial intercept invariance (Byrne, Shavelson, \& Muthén, 1989)? Such questions are, first, not unique to the growth models at hand, but in fact pervade many model types whether longitudinal or multisample. Second, while discussion of such types of invariance is in no short supply (for a nice didactic treatment see Widaman and Reise, 1997), recommendations within the methodological and applied literature regarding sufficient invariance conditions to ensure valid structure inference are without general consensus. Nor is it the purpose of this article to attempt to facilitate such consensus, either in the context of the current models or otherwise.

As is often practiced in other scenarios, for assessing second-order latent growth with shifting indicators a family of models representing different degrees of invariance may be tested, ranging from strict factorial invariance (involving all available common parameters) to a model meeting only minimum identifying constraints. Certainly if a model is selected whose constraints are inconsistent with truth, then the ability to make accurate population inferences regarding growth could become compromised. On the other hand, if a model is selected whose constraints perfectly mirror the population invariance (whether strict, partial, or in between), growth in the construct can indeed be modeled as demonstrated in the current article as long as minimum identification conditions are met. [It should be noted that these minimum conditions, while sufficient for model identification, actually render the structural parameters of interest locally just-identified; having additional common indicators across 


\section{HANCOCK \& BUEHL}

time (i.e., two or more per factor) therefore allow for improved structural assessment in terms of both testability and parameter estimation.] However, even satisfactory datamodel fit for the strictest of invariance conditions cannot guarantee that the nature of the construct is intransient, but rather can only lend support to the theory of stability of the construct's identity. That is to say, ultimately the stability of a construct's identity rests with strong theoretical foundations regarding the construct as well as the indicators themselves, for which tests of invariance may provide confirmatory evidence. For cases where a stably defined construct is hypothesized, it is expected that the methods illustrated in the current article (and the many variations thereof) will have wide-ranging applications in scenarios where developmental and/or administrative conditions have dictated the absence of common variables across all time points.

References
Bentler, P.M. (2004). EQS structural equations program. Encino, CA: Multivariate Software, Inc.

Bollen, K. A., \& Curran, P. J. (2005). Latent curve models: A structural equation perspective. NY: Wiley.

Byrne, B. M., \& Crombie, G. (2003). Modeling and testing change: An introduction to the latent growth curve model. Understanding Statistics, 2, 177-203.

Byrne, B. M., Shavelson, R. J., \& Muthén, B. (1989). Testing for the equivalence of factor covariance and mean structures: The issue of partial measurement invariance. Psychological Bulletin, 105, 456-466.

Duncan, S. C., Duncan, T. E., \& Hops, H. (1996). Analysis of longitudinal data within accelerated longitudinal designs. Psychological Methods, 1, 236-248.

Duncan, T. E., Duncan, S. C., \& Strycker, L. A. (2006). An introduction to latent variable growth curve modeling: Concepts, Issues, and Applications ( $2^{\text {nd }}$ ed.). Mahwah, NJ: Lawrence Erlbaum Associates.
Hancock, G. R., Kuo, W-L., \& Lawrence, F. R. (2001). An illustration of second-order latent growth models. Structural Equation Modeling: A Multidisciplinary Journal, 8, 470489.

Hancock, G. R., \& Lawrence, F. R. (2006). Using latent growth models to evaluate longitudinal change. In G. R. Hancock \& R. O. Mueller (Eds.), Structural equation modeling: A second course (p. 171-196). Greenwood, CT: Information Age Publishing, Inc.

Hu, L., \& Bentler, P. M. (1999). Cutoff criteria for fit indexes in covariance structure analysis: Conventional criteria versus new alternatives. Structural Equation Modeling: A Multidisciplinary Journal, 6, 1-55.

Ingels, S. J., Dowd, K. L., Baldridge, J. D., Stipe, J. L., Bartot, V. H., \& Frankel, M. R. (1994). National education longitudinal study of 1988, second follow-up: Student component data file user's manual (Report No. NCES 94374). Washington, DC: U.S. Dept. of Education, Office of Educational Research and Improvement.

Kolen, M. J., \& Brennan, R. L. (2004). Test equating, scaling, and linking: Methods and practices (2nd ed.). NY: Springer.

McArdle, J. J. (1988). Dynamic but structural equation modeling of repeated measures data. In J. R. Nesselroade \& R. B. Cattell (Eds.), Handbook of multivariate experimental psychology (2nd ed., p. 561-614). New York: Plenum Press.

McArdle, J. J. (1994). Structural factor analysis experiments with incomplete data. Multivariate Behavioral Research, 29, 409-454.

McArdle, J. J. \& Bell, R. Q. (2000). Recent trends in modeling longitudinal data by latent growth curve methods. In T. D. Little, K. U. Schnabel, \& J. Baumert (Eds.), Modeling longitudinal and multiple-group data: Practical issues, applied approaches, and scientific examples (p.69-107). Mahwah, NJ: Lawrence Erlbaum Associates, Inc.

McArdle, J. J., \& Hamagami, F. (1991). Modeling incomplete longitudinal and crosssectional data using latent growth structural equation models. In L. M. Collins \& J. L. Horn (Eds.), Best methods for the analysis of change (p. 276-304). Washington, DC: American Psychological Association. 


\section{SECOND-ORDER LATENT GROWTH MODELS WITH SHIFTING INDICATORS}

McArdle, J. J., \& Woodcock, R. W. (1997). Expanding test-retest designs to include developmental time-lag components. Psychological Methods, 2, 403-435.

Meredith, W. (1993). Measurement invariance, factor analysis and factorial invariance. Psychometrika, 58, 525-543.

Preacher, K. J.,., Wichman, A. L., MacCallum, R. C., \& Briggs, N. E (2008). Latent growth curve modeling. Thousand Oaks, CA: Sage.

Rosenberg, M. (1965). Society and the adolescent self-image. Princeton, NJ: Princeton University Press.

Ross, S. M. (2000). Introduction to probability models (7th ed.). Burlington, MA: Harcourt Academic Press.

Sayer, A.G. \& Cumsille, P. (2001). Second-order latent growth models. In L. M. Collins \& A. G. Sayer (Eds.), New methods for the analysis of change (p. 177-200). Washington, DC: American Psychological Association.
Smith, P. C., Balzer, W., Brannick, M., Chia, W., Eggleston, S., Gibson, W., et al. (1987). The revised JDI: A facelift for an old friend. The Industrial-Organizational Psychologist, 24, 31-33.

Tisak, J., \& Meredith, W. (1990). Descriptive and associative development models. In A. Von Eye (Ed.), Statistical methods in longitudinal research (Vol. 2, p. 387-406). Boston, MA: Academic Press.

Widaman, K. F., \& Reise, S. P. (1997).

Exploring the measurement invariance of psychological instruments: Applications in the substance use domain. In Kendall, J. B., Windle, M., \& West, S. G. (Eds.), The science of prevention: Methodological advances from alcohol and substance abuse research (pp. 281324). Washington, DC: American Psychological Association.

\section{Acknowledgements}

We are most grateful for the thoughtful comments, discussion, and assistance of our colleagues Eric Slud, Paul Smith, Robert Ployhart, Patrick Curran, Jack McArdle, and Kristopher Preacher. 
Appendix A

EQS syntax for full and reduced population models in Example 1

EQS syntax for Model 1 (full model):

\section{/TITLE}

Example 1, full model

/SPECIFICATIONS

cases $=100,000$; variables $=20$; matrix $=$ cov; method $=\mathrm{ml}$; analysis $=$ moment; fields $=10$;

/LABELS

$\mathrm{V} 1=\mathrm{AA} 1 ; \mathrm{V} 2=\mathrm{BB} 1 ; \mathrm{V} 3=\mathrm{CC} 1 ; \mathrm{V} 4=\mathrm{DD} 1 ; \mathrm{V} 5=\mathrm{EE} 1 ;$

$\mathrm{V} 6=\mathrm{AA} 2 ; \mathrm{V} 7=\mathrm{BB} 2 ; \mathrm{V} 8=\mathrm{CC} 2 ; \mathrm{V} 9=\mathrm{DD} 2 ; \mathrm{V} 10=\mathrm{EE} 2 ;$

$\mathrm{V} 11=\mathrm{AA} 3 ; \mathrm{V} 12=\mathrm{BB} 3 ; \mathrm{V} 13=\mathrm{CC} 3 ; \mathrm{V} 14=\mathrm{DD} 3 ; \mathrm{V} 15=\mathrm{EE} 3$;

$\mathrm{V} 16=\mathrm{AA} 4 ; \mathrm{V} 17=\mathrm{BB} 4 ; \mathrm{V} 18=\mathrm{CC} 4 ; \mathrm{V} 19=\mathrm{DD} 4 ; \mathrm{V} 20=\mathrm{EE} 4 ;$

F1 = ETA1; F2 = ETA2; F3 = ETA3; F4 = ETA4; F5 = ALPHA; F6 = BETA;

/EQUATIONS

$\mathrm{V} 1=1 \mathrm{~F} 1+0 \mathrm{~V} 999+\mathrm{E} 1$;

$\mathrm{V} 2=* \mathrm{~F} 1+* \mathrm{~V} 999+\mathrm{E} 2$;

$\mathrm{V} 3=* \mathrm{~F} 1+* \mathrm{~V} 999+\mathrm{E} 3$;

$\mathrm{V} 4=* \mathrm{~F} 1+* \mathrm{~V} 999+\mathrm{E} 4$;

$\mathrm{V} 5=* \mathrm{~F} 1+* \mathrm{~V} 999+\mathrm{E} 5$;

$\mathrm{V} 6=1 \mathrm{~F} 2+0 \mathrm{~V} 999+\mathrm{E} 6$;

$\mathrm{V} 7=* \mathrm{~F} 2+* \mathrm{~V} 999+\mathrm{E} 7$;

$\mathrm{V} 8=* \mathrm{~F} 2+* \mathrm{~V} 999+\mathrm{E} 8$;

$\mathrm{V} 9=* \mathrm{~F} 2+* \mathrm{~V} 999+\mathrm{E} 9$;

$\mathrm{V} 10=* \mathrm{~F} 2+* \mathrm{~V} 999+\mathrm{E} 10$

$\mathrm{V} 11=1 \mathrm{~F} 3+0 \mathrm{~V} 999+\mathrm{E} 11$

$\mathrm{V} 12=* \mathrm{~F} 3+* \mathrm{~V} 999+\mathrm{E} 12$

$\mathrm{V} 13=* \mathrm{~F} 3+* \mathrm{~V} 999+\mathrm{E} 13$;

$\mathrm{V} 14=* \mathrm{~F} 3+* \mathrm{~V} 999+\mathrm{E} 14$

$\mathrm{V} 15=* \mathrm{~F} 3+* \mathrm{~V} 999+\mathrm{E} 15$;

$\mathrm{V} 16=1 \mathrm{~F} 4+0 \mathrm{~V} 999+\mathrm{E} 16$;

$\mathrm{V} 17=* \mathrm{~F} 4+* \mathrm{~V} 999+\mathrm{E} 17$;

$\mathrm{V} 18=* \mathrm{~F} 4+* \mathrm{~V} 999+\mathrm{E} 18$

$\mathrm{V} 19=* \mathrm{~F} 4+* \mathrm{~V} 999+\mathrm{E} 19$;

$\mathrm{V} 20=* \mathrm{~F} 4+* \mathrm{~V} 999+\mathrm{E} 20$;

$\mathrm{F} 1=1 \mathrm{~F} 5+0 \mathrm{~F} 6+\mathrm{D} 1$;

$\mathrm{F} 2=1 \mathrm{~F} 5+1 \mathrm{~F} 6+\mathrm{D} 2$;

$\mathrm{F} 3=1 \mathrm{~F} 5+2 \mathrm{~F} 6+\mathrm{D} 3$;

$\mathrm{F} 4=1 \mathrm{~F} 5+3 \mathrm{~F} 6+\mathrm{D} 4$;

$\mathrm{F} 5=* \mathrm{~V} 999+\mathrm{D} 5$

F6 = *V999 + D6;

/VARIANCES

E1 to E20=*;

D1 to D6=*;

/COVARIANCES

D5,D6 $=*$;

$\mathrm{E} 1, \mathrm{E} 6=* ; \mathrm{E} 1, \mathrm{E} 11=* ; \mathrm{E} 1, \mathrm{E} 16=* ; \mathrm{E} 6, \mathrm{E} 11=* ; \mathrm{E} 6, \mathrm{E} 16=* ; \mathrm{E} 11, \mathrm{E} 16=* ;$

$\mathrm{E} 2, \mathrm{E} 7=* ; \mathrm{E} 2, \mathrm{E} 12=* ; \mathrm{E} 2, \mathrm{E} 17=* ; \mathrm{E} 7, \mathrm{E} 12=* ; \mathrm{E} 7, \mathrm{E} 17=* ; \mathrm{E} 12, \mathrm{E} 17=*$;

$\mathrm{E} 3, \mathrm{E} 8=* ; \mathrm{E} 3, \mathrm{E} 13=* ; \mathrm{E} 3, \mathrm{E} 18=* ; \mathrm{E} 8, \mathrm{E} 13=* ; \mathrm{E} 8, \mathrm{E} 18=* ; \mathrm{E} 13, \mathrm{E} 18=*$;

$\mathrm{E} 4, \mathrm{E} 9=* ; \mathrm{E} 4, \mathrm{E} 14=* ; \mathrm{E} 4, \mathrm{E} 19=* ; \mathrm{E} 9, \mathrm{E} 14=* ; \mathrm{E} 9, \mathrm{E} 19=* ; \mathrm{E} 14, \mathrm{E} 19=* ;$ 
HANCOCK \& BUEHL

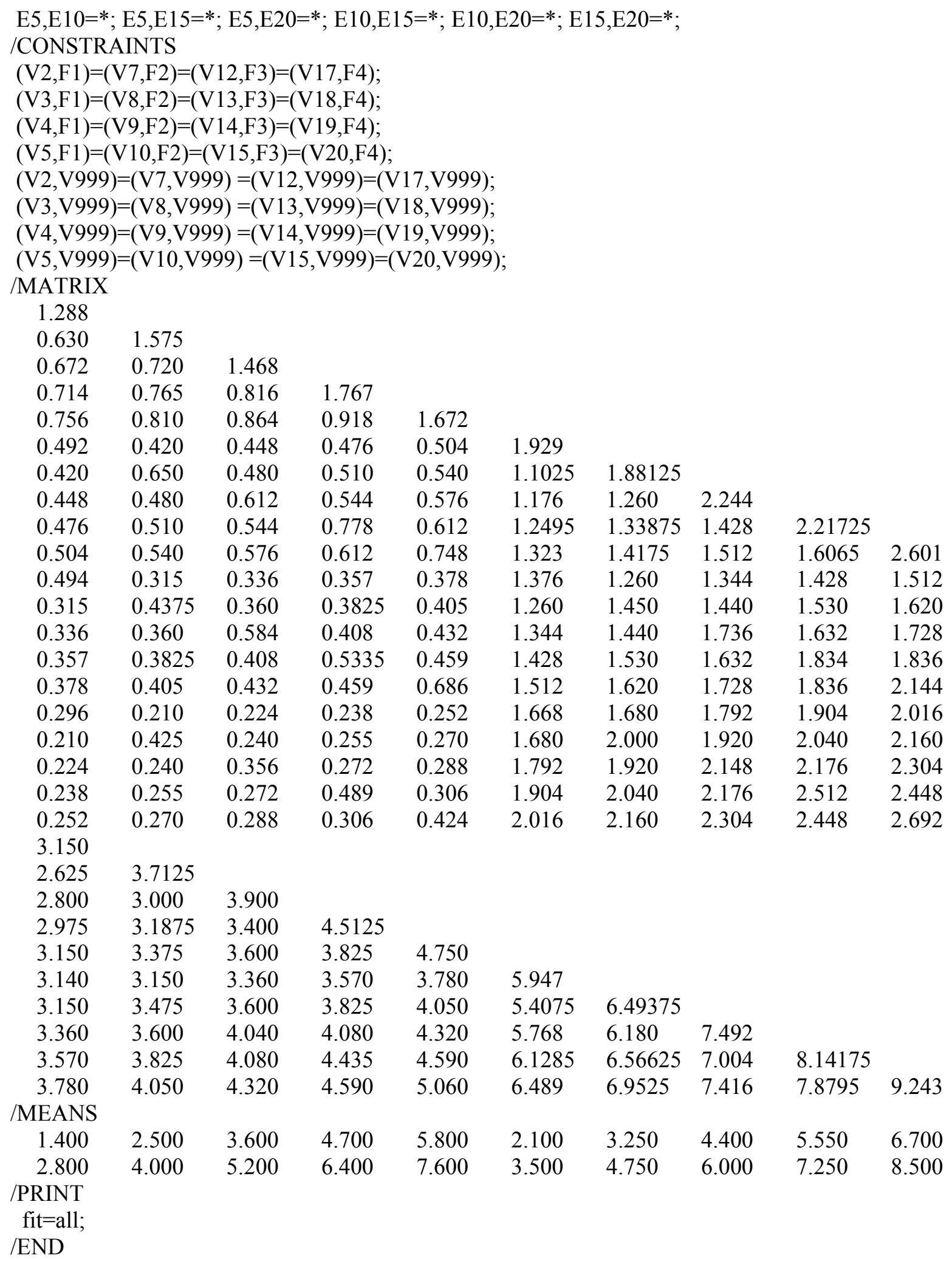


EQS syntax for Model 2 (reduced model):

/TITLE

Example 1, Model 2 (reduced model)

/SPECIFICATIONS

cases $=100,000$; variables $=8$; matrix $=\mathrm{cov}$; method $=\mathrm{ml}$; analysis $=$ moment; fields $=10$;

/LABELS

$\mathrm{V} 1=\mathrm{AA} 1 ; \mathrm{V} 2=\mathrm{BB} 1 ; \mathrm{V} 3=\mathrm{BB} 2 ; \mathrm{V} 4=\mathrm{CC} 2 ;$

$\mathrm{V} 5=\mathrm{CC} 3 ; \mathrm{V} 6=\mathrm{DD} 3 ; \mathrm{V} 7=\mathrm{DD} 4 ; \mathrm{V} 8=\mathrm{EE} 4 ;$

F1 = ETA1; F2 = ETA2; F3 = ETA3; F4 = ETA4; F5 = ALPHA; F6 = BETA;

/EQUATIONS

$\mathrm{V} 1=1 \mathrm{~F} 1+0 \mathrm{~V} 999+\mathrm{E} 1$

$\mathrm{V} 2=* \mathrm{~F} 1+* \mathrm{~V} 999+\mathrm{E} 2$;

$\mathrm{V} 3=* \mathrm{~F} 2+* \mathrm{~V} 999+\mathrm{E} 3$;

$\mathrm{V} 4=* \mathrm{~F} 2+* \mathrm{~V} 999+\mathrm{E} 4$;

$\mathrm{V} 5=* \mathrm{~F} 3+* \mathrm{~V} 999+\mathrm{E} 5$;

$\mathrm{V} 6=* \mathrm{~F} 3+* \mathrm{~V} 999+\mathrm{E} 6$;

$\mathrm{V} 7=* \mathrm{~F} 4+* \mathrm{~V} 999+\mathrm{E} 7$;

$\mathrm{V} 8=* \mathrm{~F} 4+* \mathrm{~V} 999+\mathrm{E} 8$;

$\mathrm{F} 1=1 \mathrm{~F} 5+0 \mathrm{~F} 6+\mathrm{D} 1$;

$\mathrm{F} 2=1 \mathrm{~F} 5+1 \mathrm{~F} 6+\mathrm{D} 2$;

$\mathrm{F} 3=1 \mathrm{~F} 5+2 \mathrm{~F} 6+\mathrm{D} 3$;

$\mathrm{F} 4=1 \mathrm{~F} 5+3 \mathrm{~F} 6+\mathrm{D} 4$;

$\mathrm{F} 5=* \mathrm{~V} 999+\mathrm{D} 5$;

$\mathrm{F} 6=* \mathrm{~V} 999+\mathrm{D} 6$;

/VARIANCES

$\mathrm{E} 1$ to $\mathrm{E} 8=*$;

D1 to D6=*;

/COVARIANCES

D5,D6 $=*$;

$\mathrm{E} 2, \mathrm{E} 3=* ; \mathrm{E} 4, \mathrm{E} 5=* ; \mathrm{E} 6, \mathrm{E} 7=*$;

/CONSTRAINTS

$(\mathrm{V} 2, \mathrm{~F} 1)=(\mathrm{V} 3, \mathrm{~F} 2)$;

$(\mathrm{V} 4, \mathrm{~F} 2)=(\mathrm{V} 5, \mathrm{~F} 3)$;

$(\mathrm{V} 6, \mathrm{~F} 3)=(\mathrm{V} 7, \mathrm{~F} 4)$;

$(\mathrm{V} 2, \mathrm{~V} 999)=(\mathrm{V} 3, \mathrm{~V} 999)$;

$(\mathrm{V} 4, \mathrm{~V} 999)=(\mathrm{V} 5, \mathrm{~V} 999)$;

$(\mathrm{V} 6, \mathrm{~V} 999)=(\mathrm{V} 7, \mathrm{~V} 999)$;

/MATRIX

1.288

$.630 \quad 1.575$

$\begin{array}{lll}.420 & .650 & 1.881\end{array}$

$\begin{array}{llll}.448 & .480 & 1.260 & 2.244\end{array}$

$\begin{array}{lllll}.336 & .360 & 1.440 & 1.736 & 3.900\end{array}$

$\begin{array}{lllll}.357 & .383 & 1.530 & 1.632 & 3.400\end{array}$

$\begin{array}{lllll}.238 & .255 & 2.040 & 2.176 & 4.080\end{array}$

4.513

$\begin{array}{lllll}.252 & .270 & 2.160 & 2.304 & 4.320\end{array}$

$4.435 \quad 8.142$

$\begin{array}{lll}4.590 & 7.880 \quad 9.243\end{array}$

/MEANS

1.400

2.500

3.250

4.400

5.200

$6.400 \quad 7.250$

8.500

/PRINT

fit=all;

/END 
HANCOCK \& BUEHL

\section{Appendix $B$}

EQS syntax for full NELS:88 model in Example 2




SECOND-ORDER LATENT GROWTH MODELS WITH SHIFTING INDICATORS

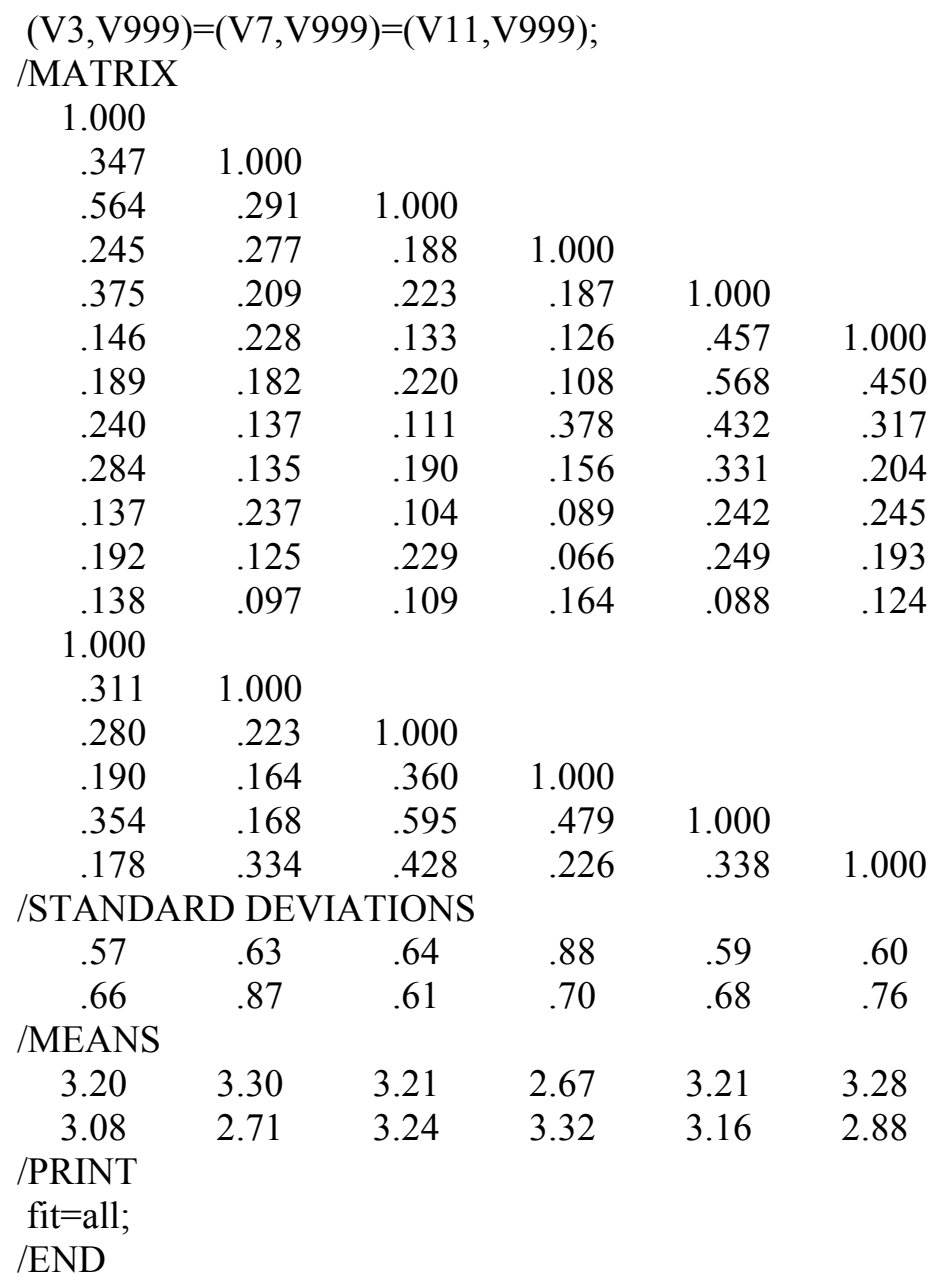

